\title{
Modelling and Simulation of Monopolar HVDC Transmission System Feeding a Strong AC Network with Firefly Algorithm based Optimal PI Controller
}

\author{
S. Singaravelu \\ Professor \\ Department of Electrical Engineering \\ Annamalai University, Annamalainagar \\ Tamilnadu - 608002, India
}

\author{
S. Seenivasan \\ Assistant Professor \\ Department of Electrical Engineering \\ Annamalai University, Annamalainagar \\ Tamilnadu - 608002, India
}

\begin{abstract}
Transmission of electrical power through high voltage direct current (HVDC) has attracted the attention of a number of researchers in the recent years. For economic design and optimal operation, HVDC system requires a detailed simulation model. Therefore, in this paper a detailed Matlab simulation model of line commutated converter (LCC) based monpolar HVDC system, feeding a strong AC network, with a fixed capacitor (FC) as a reactive power compensator is presented. Firefly algorithm based optimal proportional integral (PI) controller has been proposed for the rectifier and the inverter control. The transient performances of the HVDC system under various $\mathrm{AC}$ and DC fault conditions were studied. The results show the supremacy of the firefly algorithm based optimal PI controller over the conventional PI controller. The harmonic analysis is also carried out under steady state operation to assure the quality of power supply on the inverter AC side.
\end{abstract}

\section{Keywords}

Monopolar HVDC, Strong AC system, PI controller, Firefly Algorithm.

\section{INTRODUCTION}

The power transmission through HVDC technology is now emerging and experiencing rapid increases in the voltage, power carrying capacity and length of transmission lines [1]. While comparing with three phase HVAC transmission systems, HVDC system is commendable in the following portions: (a) HVDC line cost and operating cost are less, (b) it need not to operate synchronously between two AC systems linked by HVDC and (c) it is simple to control and adjust the power flow [2]. Generally, the HVDC system is composed of three major parts: (a) rectifier station to convert AC to DC, (b) transmission link and (c) inverter station to convert back to AC. Most of the HVDC systems have a line commutated converter [3]. The LCC-HVDC system naturally absorbs a large amount of reactive power in rectifier stations and inverter stations. By means of filters and/or reactive power compensators connected to the primary side of the converter transformer, the reactive power is supplied $[4,5]$ to HVDC systems. Various control techniques [6] are employed for the control and protection of the line and converter against faults.

The behavior of HVDC systems plays ever greater roles in the performance of entire AC/DC power systems. It is significant to thoroughly understand the mechanisms of the interactions between an HVDC system and an AC network so the HVDC system can be operated in a manner that enhances the stability of the entire power grid. The significance of this interaction largely depends on the strength of the $\mathrm{AC}$ system at the converter bus [7]. The strength of the AC system is demonstrated by its ability to maintain the voltage at the converter bus during various disturbances in the power system, such as faults etc. Their influence on station design and performance is assessed with reference to the AC-DC system strength. The system strength is generally expressed by the short circuit ratio (SCR) [8], which is defined as the ratio of the AC system short circuit capacity to DC link power: $\mathrm{SCR}=\mathrm{S} / \mathrm{P}_{\mathrm{dc}}$. Here ' $\mathrm{S}$ ' is the $\mathrm{AC}$ system three phase symmetrical short circuit level in megavolt-amperes (MVA) at the converter terminal $\mathrm{AC}$ bus with $1 \mathrm{p} . \mathrm{u} \mathrm{AC}$ terminal voltage and ' $\mathrm{P}_{\mathrm{dc}}$ ' is the rated $\mathrm{DC}$ terminal power in megawatts (MW). The SCR values [9] can be used to classify AC systems are: a) a strong AC system is categorized by $\mathrm{SCR}>3$, b) a weak AC system is categorized by $2 \leq \mathrm{SCR}<3$ and c) a very weak $A C$ system is categorized by $\mathrm{SCR}<2$.

A lot of simulation work has been carried out to know the interaction between AC network and HVDC system. The steady state and fault recovery performance of the HVDC system connected to a strong AC network has been carried out in Matlab-Simulink environment [10] during DC line fault and single phase to ground fault at inverter side. The fault recovery characteristics of the HVDC system feeding a strong AC network [11] is carried out using advanced digital power system simulator (ADPSS) during DC line fault and the inverter bus fault conditions.

The DC power recovery and suppression of temporary overvoltage (TOV) of an HVDC system feeding a weak or very weak AC network [12-14] has been discussed. To make the analysis complete, it is highly necessary to consider the suppression of TOV for an HVDC system feeding a strong AC network too. Therefore, in this simulation work both the DC power recovery performance as well as suppression of TOV during various transient fault conditions has been discussed. The harmonic investigation is also carried out under steady state to assure the quality of power supply on the inverter AC side.

Usually, the rectifier and the inverter controllers of an HVDC system are the simple fixed gain PI type of controllers. The HVDC system based on the fixed gain PI controllers causes instability under various abnormal conditions. The problems due to conventional PI controllers for converter controls are inadequate to tune its gain for different operating conditions. To overcome this drawback intelligent techniques have been introduced such as fuzzy [15], neural network [16], adaptive neuro fuzzy [17], improved particle swarm optimization [18] for proper tuning of the controller parameters. However, in all those tuning methods the principal signals used to fix the proportional and integral gains of the pole controller (both the 
rectifier and the inverter) are current error and its derivative. On the other hand, for the inverter gamma controller, the gamma error and its derivative are used as the principal signals.

In this paper, minimization of the rectifier and the inverter DC power errors are considered as an objective function to fix the proportional and integral gains of the respective PI controller.
The integral square error of the rectifier DC power error and the inverter DC power error are processed by the firefly algorithm to fix the gain of the rectifier current PI controller and to fix the gain of both the inverter current PI controller and the gamma PI controller respectively. To demonstrate the effectiveness of the firefly algorithm based optimal PI controller on transient performance of HVDC system, it has been compared with conventional PI controller.

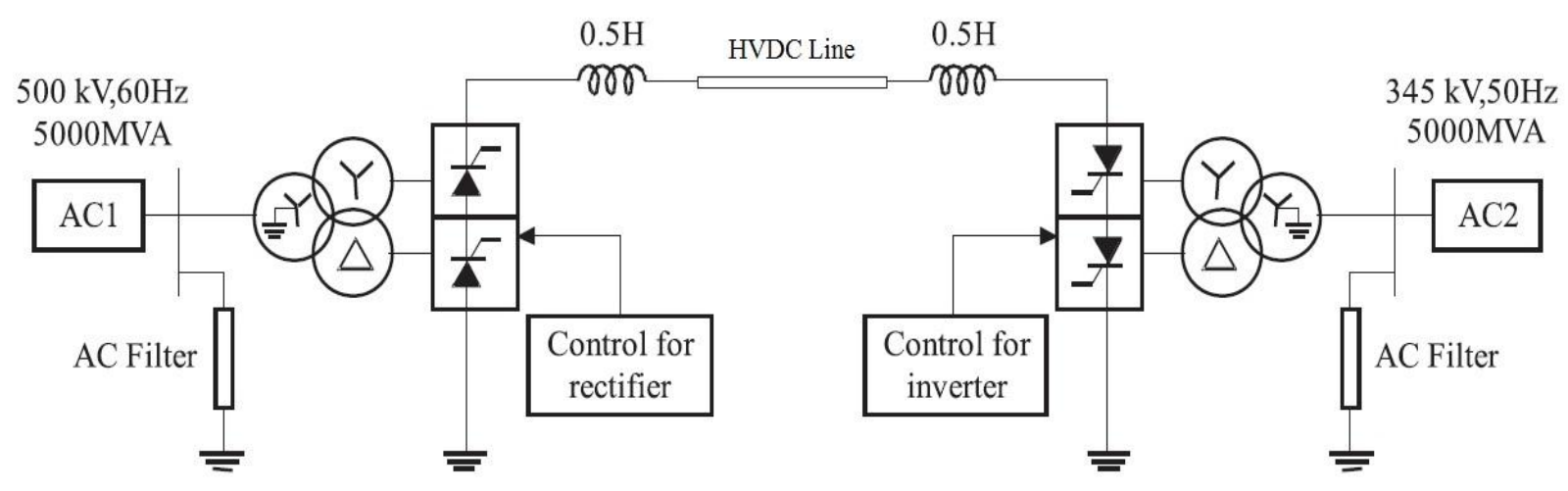

Fig 1: The monopolar HVDC transmission system feeding strong AC network

\section{MODELLING OF HVDC SYSTEM}

A line commutated converter based monopolar HVDC system of $500 \mathrm{kV}, 2 \mathrm{kA}, 1000 \mathrm{MW}$ feeding a strong AC network shown in the Fig 1.

\subsection{AC network}

The rectifier side AC system of $500 \mathrm{kV}, 5000 \mathrm{MVA}, 60 \mathrm{~Hz}$ and the inverter side AC system of $345 \mathrm{kV}, 5000 \mathrm{MVA}, 50 \mathrm{~Hz}$ are generally represented by damped LLR equivalents [19]. The double tuned filter of $300 \mathrm{MVAr}$ is used to eliminate the $11^{\text {th }}$ and $13^{\text {th }}$ order current harmonics [20]. Second order high pass filter of 150MVAr is used to eliminate the current harmonics higher than $24^{\text {th }}$. For reactive power compensation a capacitor of $150 \mathrm{MVAr}$ is used.

\subsection{Converter transformer}

The 1200MVA converter transformer on the rectifier/ the inverter side has one primary (Wye grounded) and two sets of secondary (Wye and Delta). The typical value of leakage reactance of $0.24 \mathrm{p} . \mathrm{u}$ is considered for converter transformers in the HVDC system [21]. The tap position is set at a position, determined by a duplication factor applied to the primary nominal voltage of the converter transformers $(0.90$ on the rectifier side; 0.96 on the inverter side).

\subsection{Converters}

The rectifier and the inverter are 12-pulse converters have been modelled using two universal bridge blocks [22] connected in series. The universal bridge blocks are a compact representation of a DC converter, which includes a built in 6-pulse Graetz converter bridge (can be inverter or rectifier) and Series RC snubber circuits are connected in parallel with each switching device.

\subsection{HVDC network}

The HVDC network model consists of a smoothing reactor, a passive filter of double tuned type (to mitigate the $12^{\text {th }}$ and $24^{\text {th }}$ order HVDC voltage harmonics) [23] and an HVDC link. The HVDC link of $1500 \mathrm{~km}$ is modelled as a distributed parameter line model with lumped losses. In this model, LC line is characterized by two values, namely the surge impedance and the phase velocity.

\subsection{HVDC control and protection}

The rectifier is equipped with a current controller to maintain the HVDC system current constant. The HVDC system current at the rectifier end is measured with the proper transducer and pass through the appropriate filters. After filtering, the measured current is compared to the reference current to produce the error signal. The error signal from the rectifier side, then passes through the conventional PI controller to produce firing angle order. The firing circuit which is synchronized with the AC system through phase locked loop uses the firing angle order to produce the necessary equidistant pulses for the rectifier valves.

Similarly the inverter is provided with a current controller to maintain the HVDC system current constant and a gamma controller for maintaining a constant extinction angle. The HVDC system current at the inverter end is measured with the proper transducer and pass through the appropriate filters. After filtering, the measured current is compared to the reference current to produce an error signal. The error signal from the inverter side, then passes through the conventional PI controller to produce firing angle order. For gamma controller the gamma value is measured using zero crossing information from the commutation bus voltages and the valve switching times. The gamma error is applied to another conventional PI controller, which produce the firing angle order for the inverter. The firing angle orders of the current and gamma controller are compared and the minimum is used to produce the firing pulses for the inerter valves [24].

The reference current for the current controllers are obtained from the master controller output through the voltage dependent current order limiter (VDCOL) which can reduce the reference value of direct current $\left(\mathrm{I}_{\mathrm{dref}}\right)$ in case of the large decline in direct voltage, so as to suppress the over current and maintain the system voltage. In normal state, there is a 
small margin $\left(\mathrm{I}_{\mathrm{dmarg}}\right)$ between the direct current references of the two current controllers. Since $\mathrm{I}_{\text {dref }}$ of inverter will be smaller than $I_{d r e f}$ of rectifier, the output of the current controller configured in the inverter side will be regulated to its maximum, and thus the current controller will not be selected among the two controllers (current and gamma). Therefore the gamma controller will decide the inverter's firing angle.

HVDC protection functions are implemented to protect the rectifier and the inverter. The HVDC fault protection circuit at the rectifier detects and force the delay angle into the inverter region so as to quench the fault current. The commutation failure prevention, control circuit of the inverter detects various $\mathrm{AC}$ faults and reduces the utmost delay angle limit in order to decrease the risk of commutation failure [25]. The low AC voltage detection circuit at the rectifier and the inverter serves to categorize between an $\mathrm{AC}$ fault and a DC fault.

\section{APPLICATION OF FIREFLY ALGORITHM FOR OBTAINING OPTIMAL GAIN VALUES FOR PI CONTROLLERS}

Xin-She Yang was formulated the firefly optimization algorithm [26-28], inspired by the flashing behavior of fireflies. In the firefly algorithm, the optimization process depends on the brightness of the fireflies and the movement of fireflies towards their brighter counterparts. Every firefly is attracted to the other depending on brightness because the fireflies are all unisexual according to the first assumption about artificial fireflies. The following section designates the pseudo code.

Define an initialize benchmark function $f(x), x=\left(x_{1}, \ldots, x_{d}\right)$

Generate an initial population of fireflies $x_{i}(i=1,2, \ldots, n)$

Determine light intensity for $x_{i}$ by calculating $f\left(x_{i}\right)$

Define light absorption coefficient $\gamma$

While $t<$ Maximum Generation

Make a copy of the generated firefly population for move function

$$
\begin{aligned}
& \text { For } i=1: n \text { all } n \text { fireflies } \\
& \text { For } j=1: i \text { all } n \text { fireflies } \\
& \text { If }\left(I_{j}>I_{i}\right),
\end{aligned}
$$

Move fireflies $i$ and $j$ according to attractiveness evaluating new solutions

Update light intensity for next iteration

End if

End for $j$

End for $i$

Sorting the fireflies to find the present best

End while

Begin post process for best results obtained.

The already existing firefly algorithm code was modified to evaluate the performance of the algorithm by varying the input parameters like the number of iterations and the problem dimensions. In this paper, minimization of the rectifier and the inverter DC power errors are considered as an objective function to fix the proportional and integral gains of the respective PI controller. To achieve the same DC power $\left(\mathrm{P}_{\mathrm{DCMEA}}\right)$ and its reference $\left(\mathrm{P}_{\mathrm{DCREF}}\right)$ is compared to get the error signal. The integral square error of the rectifier DC power error and inverter DC power error are processed by the firefly algorithm to fix the gain of the rectifier current PI controller and to fix the gain of the both inverter current PI controller and the gamma PI controller respectively. This optimal gain tuning approach ensures the reduced computational procedure, faster recovery and reduced TOV. The schematic diagram of the firefly algorithm based gain tuning technique is shown in Fig 2. The general flow chart for minimization of the rectifier/ the inverter DC power error function using firefly algorithm is shown in Fig 3 .

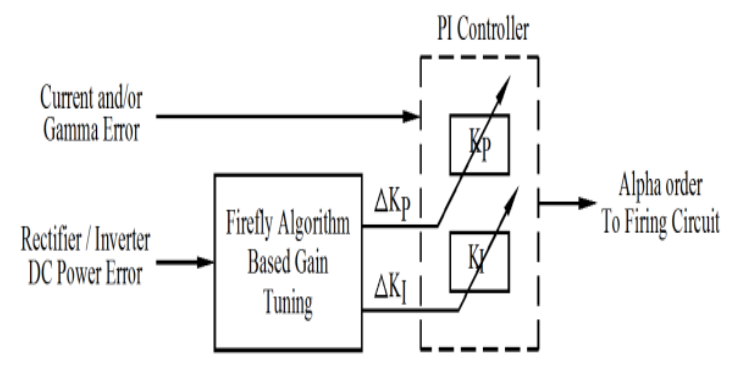

Fig 2: Schematic diagram of the firefly algorithm based gain tuning technique

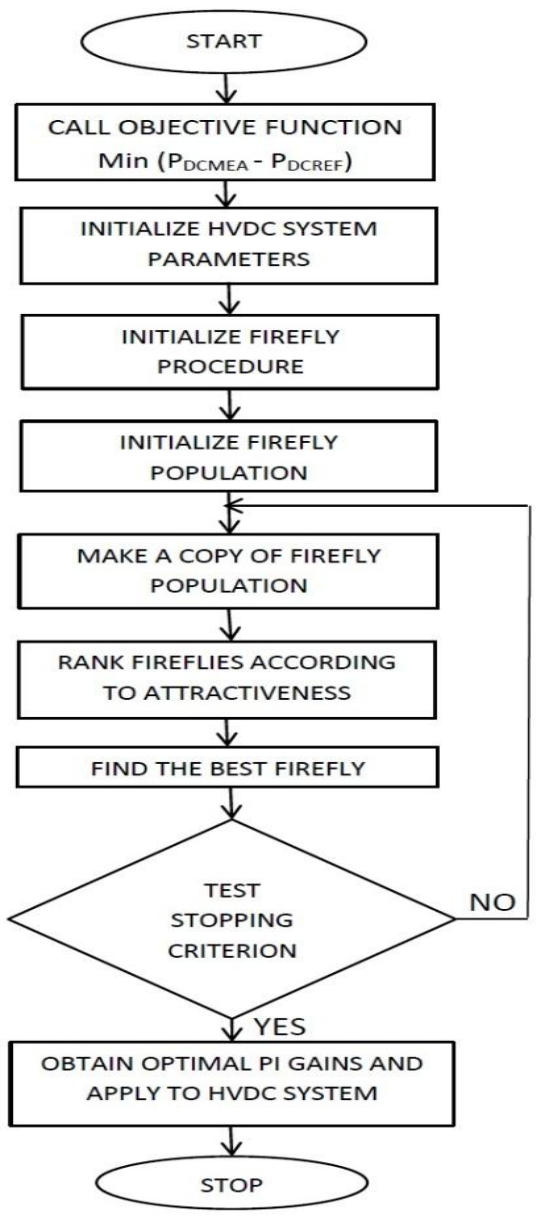

Fig 3: Flowchart for minimization of the rectifier/the inverter DC power error function using firefly algorithm 

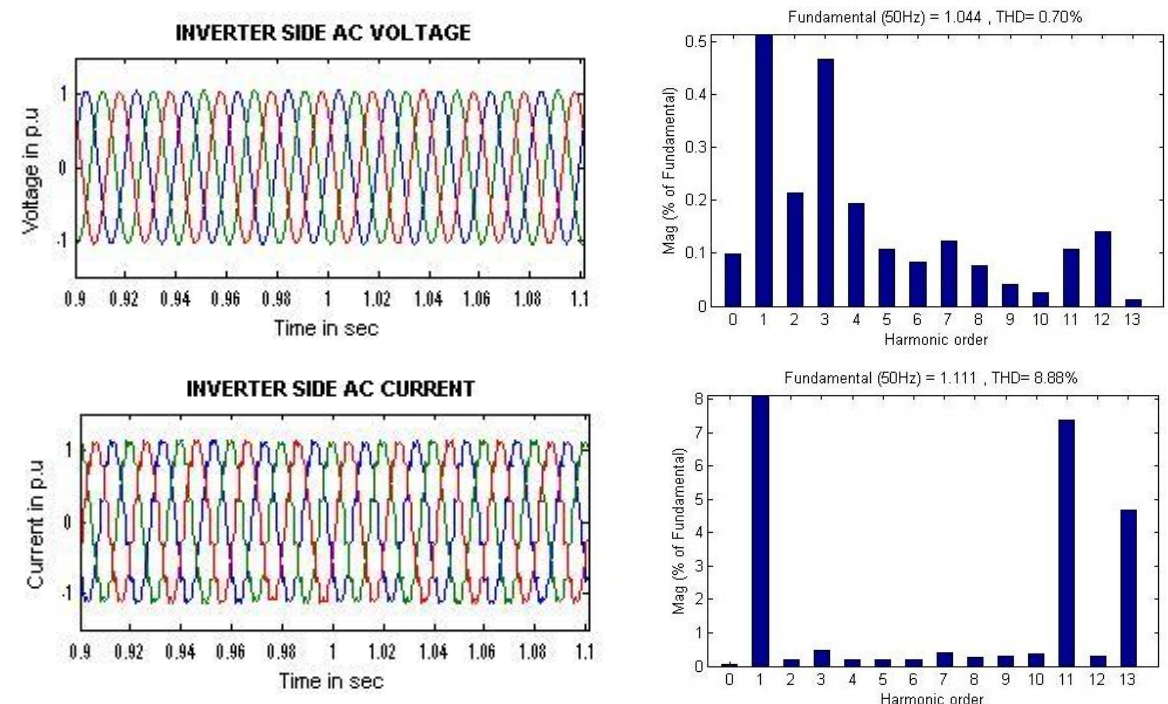

Fig 4: Inverter side AC waveforms and their harmonic spectrums during steady state operation

Table 1. Harmonics present in the inverter side $\mathrm{AC}$ quantities

\begin{tabular}{|c|c|}
\hline $\begin{array}{c}\text { Inverter Side AC } \\
\text { Quantity }\end{array}$ & \% Harmonics \\
\hline Voltage & 0.70 \\
\hline Current & 8.88 \\
\hline
\end{tabular}

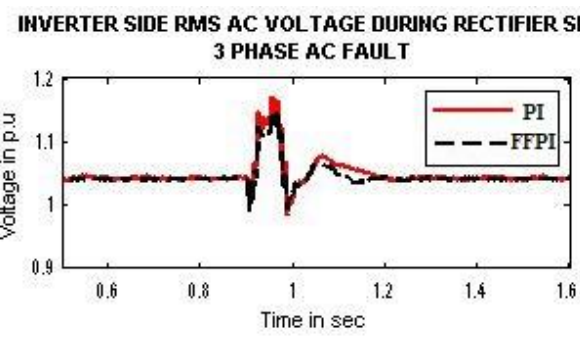

INVERTER SIDE RMS AC VOLTAGE DURIHG RECTIFIER SIDE

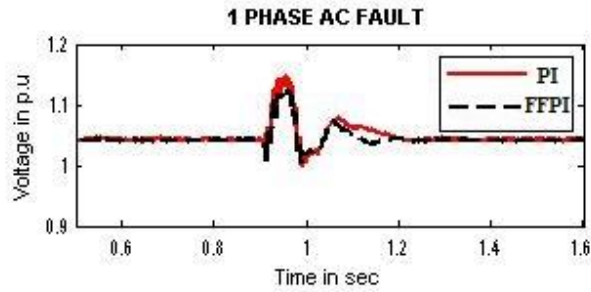

IWUERTER SIDE RMS AC VOLTAGE DURING RECTIFIER SIDE 2 PHASE AC FAULT

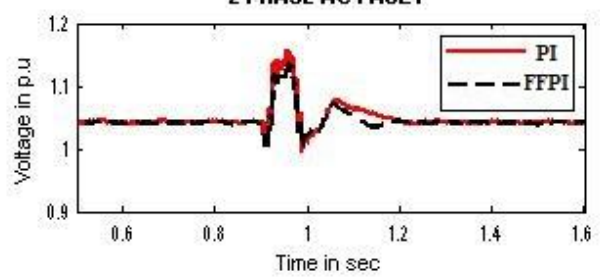

INVERTER SIDE RMS AC VOLTAGE DURING RECTIFIER DC FAULT

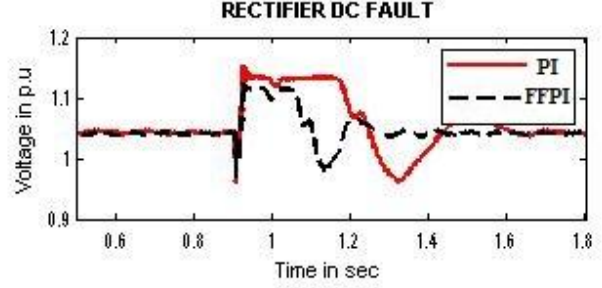

Fig 5: Inverter side RMS AC voltage waveforms when disturbances occur on the DC line or at the rectifier AC side

Table 2. The level of temporary over voltage during various disturbances on the rectifier AC and DC side

\begin{tabular}{|c|c|c|c|c|c|}
\hline \multicolumn{2}{|c|}{ Type of fault } & 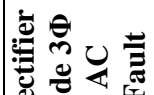 & 离 & 氖 & 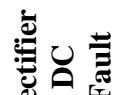 \\
\hline \multirow{2}{*}{$\begin{array}{c}\text { The level of } \\
\text { temporary over } \\
\text { voltage in p.u }\end{array}$} & PI & 1.1745 & 1.1611 & 1.1492 & 1.1538 \\
\hline & FFPI & 1.1502 & 1.1386 & 1.1266 & 1.1242 \\
\hline
\end{tabular}




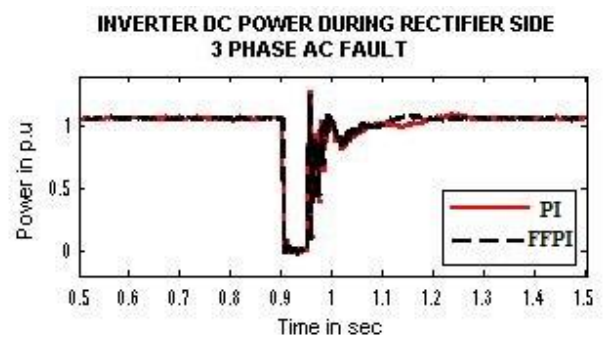

INVERTER DC POWER DURING RECTIFIER SIDE

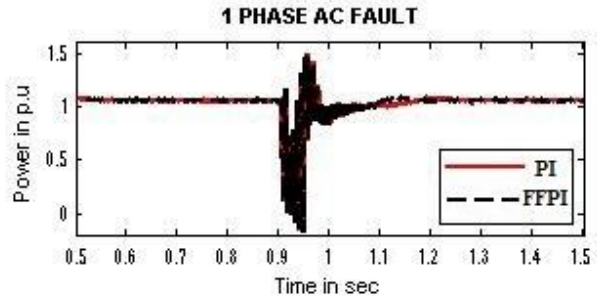

INUERTER DC POWER DURING INVERTER DC FAULT

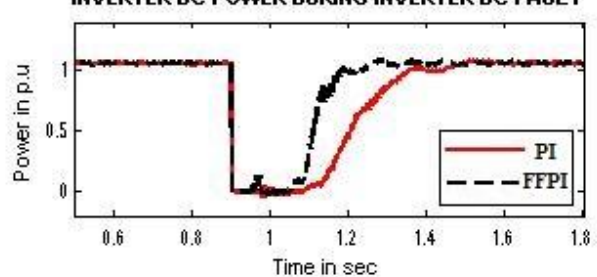

IWVERTER DC POWER DURING IWVERTER SIDE 2 PHASE AC FAULT

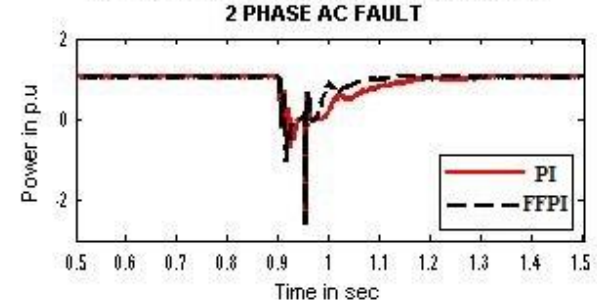

IWVERTER DC POWER DURIUG RECTIFIER SIDE 2 PHASE AC FAULT

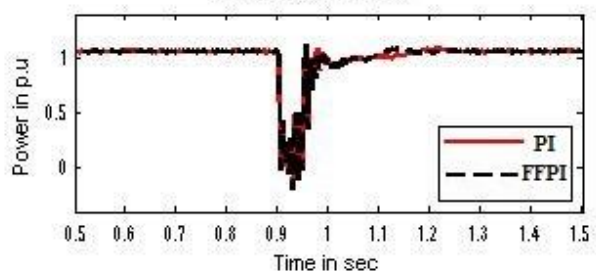

IWUERTER DC POWER DURIHG RECTIFIER DC FAULT

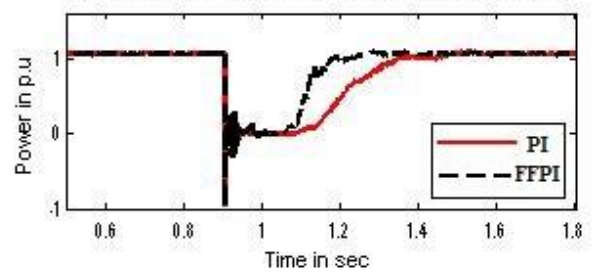

INVERTER DC POWER DURIWG INVERTER SIDE 3 PHASE AC FAULT

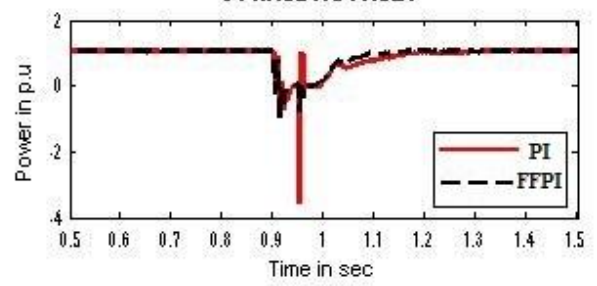

INVERTER DC POWER DURING INVERTER SIDE

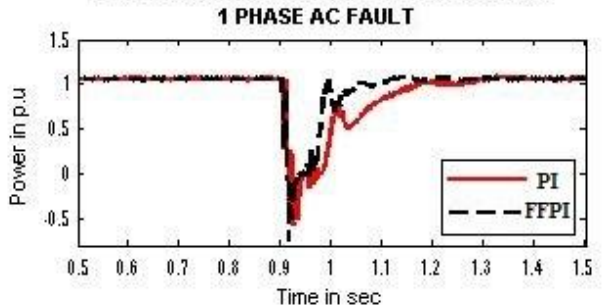

Fig 6: Inverter DC power when AC and DC disturbances occur on the rectifier side and the inverter side

Table 3. Inverter DC power recovery time when AC and DC disturbances occur on the rectifier side and the inverter side

\begin{tabular}{|c|c|c|c|c|c|c|c|c|c|}
\hline \multicolumn{2}{|c|}{ Type of fault } & 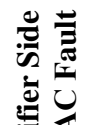 & 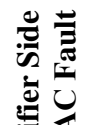 & 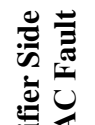 & $\stackrel{\varrho}{0}$ & 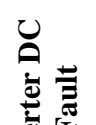 & 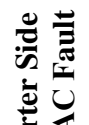 & 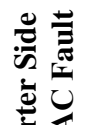 & 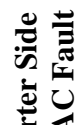 \\
\hline \multirow{2}{*}{$\begin{array}{l}\text { DC power } \\
\text { recovery time } \\
\text { in seconds }\end{array}$} & PI & 0.034 & 0.013 & 0.008 & 0.332 & 0.330 & 0.165 & 0.149 & 0.142 \\
\hline & FFPI & 0.030 & 0.010 & 0.006 & 0.204 & 0.202 & 0.101 & 0.080 & 0.068 \\
\hline
\end{tabular}

\section{SIMULATION RESULTS AND DISCUSSION}

Wide simulation work has been carried out with the proposed model, to know the interaction between AC network and HVDC system. The HVDC system model is implemented in the working platform of Matlab based on the data [29]. The transient performance of the HVDC system is analyzed for a duration of two seconds under various fault conditions, to study the suppression of TOV and fault recovery. For the purposes of comparison, identical fault duration of 0.05 seconds was used for all types of faults. The inverter side
RMS AC voltage waveforms are observed during various AC faults and DC fault on the rectifier side to study the TOV suppression capability of the firefly algorithm based PI controller. For analyzing the fault recovery capability with the firefly algorithm based PI controller, the inverter DC power is observed under various AC faults and DC fault at rectifier and inverter side. The TOV suppression and fault clearance capability of the firefly algorithm based PI controller are compared with conventional PI controller based HVDC transmission system. The steady state operation of the system has been also validated by observing harmonics present in the inverter side $\mathrm{AC}$ voltage and current. 


\subsection{Inverter side AC harmonics}

The inverter side AC voltage and current waveforms and their harmonic spectrums during steady state operation are shown in Fig 4 and the results are presented in table 1. From the inverter side $\mathrm{AC}$ waveforms and their harmonic spectrums, it is found that voltage and current are equal to 1p.u and the harmonics are within tolerable limit. The $11^{\text {th }}$ and $13^{\text {th }}$ current harmonics are the foremost harmonics on the inverter $\mathrm{AC}$ side.

\subsection{Temporary overvoltage}

When disturbances occur on the DC line or at the rectifier side, commonly TOV occurs. It is usual practice a large number RLC based filters are provided in the inverter side of the HVDC system, in order to supply the part of necessary reactive power. During the rectifier side AC or DC faults (the inverter side has no faults), the DC is blocked, and hence the reactive power of those filters will flow into the AC system, which often causes TOV. In order to suppress the TOV, the reactive power compensator and the DC system PI controllers should respond quickly otherwise the TOV could be very high and could damage the insulation of the equipment. In this paper, FC is used for reactive power compensation, therefore the ability of TOV suppression is depend on the DC system PI controller. The occurrence of TOV demonstrated with the firefly algorithm based PI controller and also compared to the conventional PI controller. From the inverter side RMS AC voltage waveforms shown in Fig 5 and the results presented in table 2, the occurrence of TOV can be understood with the presence of a conventional PI controller. The TOV values further reduced due to the application firefly algorithm based optimal PI controller compared to the conventional PI controller.

\subsection{Fault recovery}

The time taken by the HVDC system to recover the $80 \%$ of the pre-fault power after the fault clearance is known as the DC power recovery time. The DC power recovery time is often desired the recovery ability of a DC system PI controller and the capability of reactive power compensators during system disturbances. From the inverter DC power recovery simulation results (fig 6 and table 3), it is observed that the during rectifier side $\mathrm{AC}$ system faults, the system recovery with the firefly algorithm based PI controller is slightly faster than the conventional PI controller. On the other hand, for the faults in the rectifier DC side, the inverter AC and DC sides, the firefly algorithm based optimal PI controller makes the system recovery much faster than the conventional PI controller.

\section{CONCLUSION}

This paper has evidently established a well-developed, detailed simulation model of monopolar LCC-HVDC transmission system with firefly algorithm based optimal PI controller for the rectifier and the inverter control. This involvement could be very useful for designing and safeguarding persons, to analyze the interaction between AC network and HVDC system under different operating environments. The HVDC transmission system model was implemented in the Matlab environment. The transient performances of the HVDC system were analyzed under various fault conditions to study the suppression of TOV and fault recovery. Simulation results show that detailed model has tolerable accuracy and display the superiority of firefly algorithm based PI controller over the conventional fixed gain PI controller on transient performances. The harmonic analysis outcome also assures the quality of power supply on the inverter $\mathrm{AC}$ side.

\section{ACKNOWLEDGEMENT}

The authors gratefully acknowledge the support and facilities provided by the authorities of Annamalai University, Annamalainagar, Tamilnadu, India to carry out this research work.

\section{REFERENCES}

[1] G. D. Kamalapur, V. R. Sheelavant, S. Hyderabad, A. Pujar, 2014, HVDC Transmission in India, IEEE Potentials, vol. 33, no. 1, pp. 22-27.

[2] K. Meah, S. Ula, 2007, Comparative Evaluation of HVDC and HVAC Transmission Systems, IEEE General Meeting on Power Engineering Society, pp. 1-5.

[3] C. Hahn, A. Semerow, M. Luther, O. Ruhle, 2014, Generic Modeling of a Line Commutated HVDC System for Power System Stability Studies, IEEE T and D Conference and Exposition, pp. 1-6.

[4] M. Szechtman, T. Wess, C. V. Thio, 1991, A Benchmark Model for HVDC System Studies, IET International Conference on AC and DC Power Transmission, pp. 374-378.

[5] M. O. Farque, Y. Zhang, V. Dinavahi, 2006, Detailed Modeling of CIGRE HVDC Benchmark System using PSCAD / EMTDC and PSB/SIMULINK, IEEE Transactions on Power Delivery, vol. 21, no. 1, pp. 378-387.

[6] R. Hassan, S. Shah, J. Sun, 2013, HVDC Transmission System Architectures and Control-A Review, IEEE Workshop on Control and Modelling for Power Electronics, pp. 1-8.

[7] P. Kundur, 1993, Power System Stability and Control, TATA McGraw-Hill Publishing Company Limited, New Delhi.

[8] A. Gavrilovic, 1991, AC/DC System Strength as Indicated by Short Circuit Ratios, AC/DC Conference, pp. 27-32.

[9] S. Rao, 2003, EHV-AC HVDC Transmission and Distribution Engineering, Khanna publishers, New Delhi, India.

[10] S. A. Zidi, S. Hadjeri, M. K. Fellah, 2004, The Performance Analysis of an HVDC Link, Electronic Journal, Technical Acoustics, vol. 11

[11] L. Chen, K. J. Zhang, Y. J. Xia, G. Hu, 2013, Hybrid Simulation of $\pm 500 \mathrm{kV}$ HVDC Power Transmission Project Based on Advanced Digital Power System Simulator, Journal of Electronic Science and Technology, vol. 11, no. 1, pp. 66-71.

[12] S. Nyati, S. R. Atmuri, D. Gordon, D. V. Koschik, R. M. Mathur, 1988, Comparison of Voltage Control Devices at HVDC Converter Stations Connected to Weak AC Systems, IEEE Transactions on Power Delivery, vol. 3, no. 3, pp. 684-693.

[13] O. B. Nayak, A. M. Gole, 1994, Dynamic Performance of Static and Synchronous Compensators at an HVDC Inverter Bus in a Very Weak AC System, IEEE Transactions on Power Delivery, vol. 9, no. 3, pp 1350-1358. 
[14] Y. Zhuang, R. W. Menzies, 1996, Dynamic Performance of a STATCON at the HVDC Inverter Feeding a Very Weak AC System, IEEE Transactions on Power Delivery, vol. 11, no. 2, pp. 958-964.

[15] A. Routray, P. K. Dash, S. K. Panda, 1996, A Fuzzy Self-Tuning PI Controller for HVDC Links, IEEE Transactions on Power Electronics, vol. 11, no. 5, pp. 699-679.

[16] P. K. Dash, A. Routary, S. Mishra, 1999, A Neural Network based Feedback Linearising Controller for HVDC Links, Electrical Power Systems Research, vol. 50, no. 2, pp. 125-132.

[17] N. Bawane, A. G. Kothari, D. P Kothari, 2005, ANFIS Based HVDC Control and Fault Identification of HVDC converter, HAIT Journal of Science and Engineering, vol. 2 , no. 5-6, pp. 673-689.

[18] X. Zhou, C. Chen, F. Yang, M. Chen, 2009, Optimization Design of Proportional-Integral Controllers in High-voltage DC System Based on an Improved Particle Swarm Optimization Algorithm, Electric Power Components and Systems, vol. 37, no. 1, pp. 78-90.

[19] S. A. Zidi, S. Hadjeri, M. K. Fellah, 2005, Dynamic Performance of an HVDC Link", Journal of Electrical Systems, no. 1-3, pp. 15-23.

[20] X. Yao, 1998, Algorithm for Parameters of Double Tuned Filter, IEEE Conference on Harmonic and Quality of Power, vol. 1, pp. 154-157.

[21] G. Bhuvaneswari, B. C. Mahanta, 2009, Analysis of Converter Transformer Failure in HVDC Systems and Possible Solutions, IEEE Transactions on Power Delivery, vol. 24, no. 2, pp. 814-821.
[22] R. Kumar, T. Leibfried, 2005, Analytical Modelling of HVDC Transmission System Converter using Matlab/Simulink, IEEE Technical conference on Industrial and Commercial Power Systems, pp. 140-146.

[23] R. H. Lasseter, F. W. Kelley, C. B. Lindh, 1977, DC Filter Design Methods for HVDC Systems, IEEE Transactions on Power Apparatus and Systems, vol. 96, no. 2, pp. $571-578$.

[24] K. R. Padiyar, 1993, HVDC Power Transmission Systems: Technology and System Interactions, New Age International (P) Limited, and Publishers, New Delhi, India.

[25] L. Zhang, L. Dofnas, 2002, A Novel Method to Mitigate Commutation Failures in HVDC Systems, IEEE International Conference on power system technology, vol. 1, pp. 51-56.

[26] X. S. Yang, 2010, Engineering Optimization: An Introduction to Metaheuristic Applications, Wiley.

[27] X. S. Yang, 2009, Firefly Algorithms for Multimodal Optimization, Stochastic Algorithms: Foundations and Applications - Springer Berlin Heidelberg, vol. 5792, pp. 169-178.

[28] X. S. Yang, X. He, 2013, Firefly Algorithm: Recent Advances and Applications, International Journal of Swarm Intelligence, vol. 1, pp. 36-50.

[29] C. Dufour, J. Mahseredjian, J. Belanger, A Combined State-Space Nodal Method for the Simulation of Power System Transients, 2011, IEEE Transactions on Power Delivery, vol. 26, no. 2, pp. 928-935. 